\title{
Medium optimization for chitinase production from Trichoderma virens using central composite design
}

\begin{abstract}
Medium development for chitinase production by Trichoderma virens was first carried out using conventional method of one-factor-at-a-time. The medium was further optimized using Central Composite Design in which response surface was generated later from the derived model. An experimental design of four variables including various initial $\mathrm{pH}$ values, chitin, ammonium sulphate, and methanol concentrations were created using Design Expert ${ }^{\circledR}$ Software, Version 6.0. The design consists of 30 experiments, which include 6 replicates at center points. The optimal value for each variable are $3.0 \mathrm{~g} / \mathrm{L}$, chitin; $0.1 \mathrm{~g} / \mathrm{L}$, ammonium sulphate; $0.4 \%(\mathrm{v} / \mathrm{v})$, methanol; and initial $\mathrm{pH}, 4.0$ with predicted chitinase activity of 0.1495 $\mathrm{U} / \mathrm{mL}$. These predicted parameters were tested in the laboratory and the final chitinase activity obtained was $0.1471 \mathrm{U} / \mathrm{mL}$, which is almost reaching the predicted value. The optimal medium design showed an improvement of chitinase activity of $80.9 \%$ compared to activity obtained from the original Absidia medium composition.
\end{abstract}

Keyword: Chitinase; Trichoderma virens; Response surface methodology; Optimisation; Experimental design; Central composite design 